\title{
Comparison of urinary monitoring, faecal monitoring and erythrocyte analysis of stable isotope labels to determine magnesium absorption in human subjects
}

\author{
Torsten Bohn ${ }^{1 *}$, Thomas Walczyk ${ }^{1}$, Lena Davidsson ${ }^{1}$, Wolfgang Pritzkow ${ }^{2}$, Patrick Klingbeil ${ }^{2}$, \\ Jochen Vogl ${ }^{2}$ and Richard F. Hurrell \\ ${ }^{1}$ Swiss Federal Institute of Technology (ETH), Institute of Food Science and Nutrition, \\ Laboratory for Human Nutrition, 8803 Rüschlikon, Switzerland \\ ${ }^{2}$ German Federal Institute for Materials Research and Testing (BAM), 12205 Berlin, Germany
}

(Received 5 May 2003 - Revised 2 September 2003 - Accepted 12 September 2003)

\begin{abstract}
We have evaluated urinary monitoring and erythrocyte analysis to determine $\mathrm{Mg}$ absorption in human subjects as alternatives to the conventional technique of faecal monitoring by stable-isotope techniques. Ten healthy adults received $2 \cdot 2 \mathrm{mmol}{ }^{25} \mathrm{Mg}$ in water, together with wheat bread, followed 15 min later by intravenous injection of $0.6 \mathrm{mmol}{ }^{26} \mathrm{Mg}$ (day 1 ). Brilliant blue and $\mathrm{Yb}$ (given on day 0 and day 1 respectively) served as qualitative and quantitative faecal markers. Urine was collected for $6 \mathrm{~d}$ after test meal intake. Complete collections of faeces were made until excretion of the second brilliant blue marker (given on day 7). Mg isotope ratios were determined by thermal ionisation-MS in urine and faeces and by inductively coupled plasma-MS in erythrocytes. Absorption was determined based on: (1) 6d urine pools; (2) $24 \mathrm{~h}$ urine pools (collected $22-46 \mathrm{~h}$ after test meal intake); (3) erythrocytes from a blood sample drawn on day 14; (4) complete $6 \mathrm{~d}$ faecal pools; (5) faecal pools based on the first three consecutive stools after excretion of the first brilliant blue marker. Differences in mean Mg absorption (4244\%) were statistically insignificant between techniques, except when based on $6 \mathrm{~d}$ urine pools for which the value was significantly lower (33 (SD 7) \%, P=0.0003, ANOVA). The results indicate that Mg absorption can be determined from $24 \mathrm{~h}$ urine pools or erythrocytes obtained $14 \mathrm{~d}$ after test meal intake, an alternative method to the more time-consuming and labourintense faecal monitoring. The choice of technique depends on practical and financial considerations.
\end{abstract}

Magnesium absorption: Stable isotopes: Faecal monitoring: Urinary monitoring: Erythrocytes

Inadequate intake of $\mathrm{Mg}$ and low serum $\mathrm{Mg}$ levels have been discussed in relation to major public health problems such as osteoporosis (Abraham, 1991), coronary artery disease (Karppanen, 1981) and non-insulin-dependent diabetes mellitus (Kao et al. 1999). Although information about dietary intake of $\mathrm{Mg}$ is available in many industrialised countries, very little is known about $\mathrm{Mg}$ bioavailability and the influence of diet composition on $\mathrm{Mg}$ absorption. The lack of information is at least partly due to the lack of suitable methodologies to investigate $\mathrm{Mg}$ metabolism in human subjects. The chemical-balance technique is not a useful tool, as absorption from single meals cannot be determined; although radioactive isotopes have been shown to be useful to study the absorption of minerals such as $\mathrm{Ca}$ (DeGrazia et al. 1965) and $\mathrm{Zn}$ (Arvidsson et al. 1978), $\mathrm{Mg}$ radioisotopes have half-lives that are too short $(<21 \cdot 3 \mathrm{~h})$ to be useful.

Stable-isotopes techniques, however, can be used as $\mathrm{Mg}$ has three stable isotopes, two of them with low enough natural abundances to be employed as enriched labels: ${ }^{25} \mathrm{Mg}$ and ${ }^{26} \mathrm{Mg}$ (10.0 and $11.0 \%$ natural abundance respectively; Catanzaro, 1966). The technique most often used to determine $\mathrm{Mg}$ absorption is based on faecal monitoring of non-absorbed stable isotope label. This technique has been applied to measure $\mathrm{Mg}$ absorption in human subjects in several studies (Schwartz et al. 1978, 1984; Schuette et al. 1993; Tahiri et al. 2001; Sabatier et al. 2003). A second isotope label can be injected intravenously so as to estimate the absorbed and re-excreted isotope label during the faecal collection period. By correcting apparent absorption (AA) of $\mathrm{Mg}$ via excretion of the intravenous label in faeces, true absorption (TA) of $\mathrm{Mg}$ as the fraction of isotopic label absorbed by the intestine can be calculated. A major drawback of faecal monitoring, however, is the need for complete faecal collections over several consecutive days. Non-absorbable rare earth elements as quantitative faecal markers have therefore been introduced, allowing the possibility

\footnotetext{
Abbreviations: AA, apparent absorption; ICP, inductively coupled plasma; TA, true absorption.

* Corresponding author: Dr Torsten Bohn, present address, Ohio State University, Food Science and Technology Building, 2015 Fyffe Road, Columbus, OH 43210, USA, fax +16142920218, email bohn.22@osu.edu
} 
of a reduced collection period (Schuette et al. 1993; Fairweather-Tait et al. 1997).

Urinary monitoring of an oral administered $\mathrm{Mg}$ isotopic label and a second intravenously injected $\mathrm{Mg}$ isotopic label was been introduced by Schwartz and colleagues as an alternative technique to determine the $\mathrm{TA}$ of $\mathrm{Mg}$ in human subjects (Schwartz et al. 1978, 1984). The first applications were limited by the precision in isotopic analysis achievable by neutron activation analysis and GCMS. With the wider availability of thermal ionisation MS and inductively coupled plasma (ICP)-MS for high-precision $\mathrm{Mg}$ isotope-ratio measurements, urinary monitoring has been shown recently to be a potentially useful technique (Abrams \& Wen, 1999; Sabatier et al. 2003).

Techniques based on erythrocyte incorporation of isotope labels are routinely used to measure the TA of $\mathrm{Fe}$ either with radioisotope labels (Cook et al. 1972) or stable isotope labels (Kastenmayer et al. 1994), as most of newly absorbed $\mathrm{Fe}$ is incorporated into this tissue. Although erythrocytes are not a specific target tissue for $\mathrm{Mg}$, their $\mathrm{Mg}$ concentration is relatively high, approximately $2.5 \mathrm{mmol} / \mathrm{l}$ (Durlach, 1988). Coudray et al. (1997) reported erythrocyte analysis after administration of stable $\mathrm{Mg}$ isotope labels to be a useful method to determine $\mathrm{Mg}$ absorption in rats.

The aim of the present study was to compare the TA of $\mathrm{Mg}$ in healthy adult human subjects as determined by different $\mathrm{Mg}$ double-stable-isotope techniques. Measurements were based on isotope ratios in $6 \mathrm{~d}$ and $24 \mathrm{~h}$ urine pools and erythrocytes after oral and intravenous administration of two different isotope labels $\left({ }^{25} \mathrm{Mg}\right.$ and $\left.{ }^{26} \mathrm{Mg}\right)$. Faecal monitoring as the established technique to assess the TA of $\mathrm{Mg}$ in human subjects has been chosen as the reference technique for comparison. TA has been determined by faecal monitoring based on $6 \mathrm{~d}$ pools as the conventional approach and based on three-stool pools corrected for the recovery of $\mathrm{Yb}$ (a non-absorbable faecal marker) to evaluate whether the stool collection period can be shortened.

\section{Materials and methods}

\section{Subjects}

Ten apparently healthy, free-living subjects (five men, five women; BMI 21.2 (SD 3.7) kg/m², age 35.0 (SD 10.0) years) were recruited for the study. No lactating or pregnant women were included and no medication was allowed, except for oral contraceptives. Intake of mineral and/or vitamin supplements was not permitted 2 weeks before and during the study. The subjects were informed orally and in written form about the aims and the procedures of the study and written informed consent was obtained. The study protocol was reviewed and approved by the Ethical Committee of the Swiss Federal Institute of Technology, Zurich.

\section{Isotope labels}

Highly enriched ${ }^{25} \mathrm{MgO}\left({ }^{24} \mathrm{Mg} 1.04\right.$ (SD 0.01), ${ }^{25} \mathrm{Mg} 98.73$ (SD 0.01), ${ }^{26} \mathrm{Mg} \mathrm{0.23} \mathrm{(SD} \mathrm{0.01)} \mathrm{\% )} \mathrm{and}{ }^{26} \mathrm{MgO}\left({ }^{24} \mathrm{Mg} \mathrm{0.39}\right.$
(SD 0.01), ${ }^{25} \mathrm{Mg} \mathrm{0.11} \mathrm{(SD} \mathrm{0.01),}{ }^{26} \mathrm{Mg} 99.51$ (SD 0.01)\%) were purchased from Chemgas, Paris, France. ${ }^{25} \mathrm{MgO}$ $(29.3 \mathrm{mmol})$ was dissolved in $2.5 \mathrm{ml} 4 \mathrm{M}-\mathrm{HCl}$ and diluted to $100 \mathrm{ml}$ with water to be served as an orally ingested label. The $\mathrm{pH}$ of the solution was adjusted to $4-5$ by addition of an aqueous $\mathrm{NaHCO}_{3}$ (Merck, Darmstadt, Germany) solution.

Doses for intravenous administration were prepared at the Cantonal Pharmacy, Zurich, Switzerland. Sterile water and sterile materials were used for their preparation. ${ }^{26} \mathrm{MgO}(9.5 \mathrm{mmol})$ was dissolved in $2.5 \mathrm{ml} 4 \mathrm{M}-\mathrm{HCl}$, diluted with water to $50 \mathrm{ml}$ and adjusted to $\mathrm{pH} 6$ as described earlier. The sterile filtered solution was divided into individual doses of $3.2 \mathrm{ml}$ (about $0.6 \mathrm{mmol}{ }^{26} \mathrm{Mg}$ ), transferred into glass vials, capped and sealed. The $\mathrm{Mg}$ concentration of the ${ }^{25} \mathrm{Mg}$ and ${ }^{26} \mathrm{Mg}$ isotope label in solution was determined by isotope dilution using thermal ionisation-MS against a commercial $\mathrm{Mg}$ standard of natural isotopic composition (Titrisol; Merck).

Unless otherwise noted, all chemicals were of analytical grade, and all acids were further purified by surface distillation. Only $18 \mathrm{M} \Omega$ water (Milli Q water system; Millipore, Zurich, Switzerland) was used for laboratory work and test meal preparation.

\section{Test meal}

The standardised breakfast consisted of wheat bread rolls, prepared from $75 \mathrm{~g}$ white flour, using a standard recipe. A relatively long fermentation $(5 \mathrm{~h})$ was used to degrade phytic acid, a potential inhibitor of $\mathrm{Mg}$ absorption. Bread rolls were prepared in bulk and stored frozen. Water $(200 \mathrm{~g})$ was served as a drink, to which 2.20 (range $2 \cdot 03-2 \cdot 31$ ) $\mathrm{mmol}{ }^{25} \mathrm{Mg}$ and 25.4 (range 25.3-26.5) $\mu \mathrm{mol}$ $\mathrm{Yb}$ (as $\mathrm{YbCl}_{3} \cdot 6 \mathrm{H}_{2} \mathrm{O}$; Aldrich, Buchs, Switzerland) were added in solution. The amount of ingested isotope labels and $\mathrm{Yb}$ was determined by weighing.

\section{Study design}

Urine and faecal spot samples were collected on the day before the test meal administration to determine baseline $\mathrm{Mg}$ isotopic ratios. A gelatine capsule containing about $100 \mathrm{mg}$ brilliant blue (Warner Jenkinson Europe, King's Lynn, Norfolk, UK) was administered orally to mark the start of the faecal collection period. Venous blood samples $(10 \mathrm{ml})$ were drawn into heparinised glass tubes (Vacutainer Systems, Plymouth, Devon, UK) for plasma Mg analysis. The test meal was served after an overnight fast. Subjects were instructed to eat half of the bread before drinking the labelled water in order to slow down gastrointestinal passage of the isotope label. Fifteen minutes after test meal intake, 0.60 (range $0.57-0.65$ ) $\mathrm{mmol}{ }^{26} \mathrm{Mg}$ was administered intravenously. A sterile injection system consisting of a two-way catheter and a septum injection port was used. The isotope label solution was transferred quantitatively by flushing the system with physiological saline $(10 \mathrm{ml}, 9 \mathrm{~g} \mathrm{NaCl} / \mathrm{l})$. The amount of injected isotope label was determined by weighing the syringe before and after injection. No food or drink was allowed for $3 \mathrm{~h}$ following breakfast. Standardised meals were provided for lunch 
(lasagne) and dinner (pizza) on day 1. Water (2 litres) was provided as the only beverage for day 1 . No additional food was allowed on day 1 . From day 2 onwards, diet was unrestricted. To standardise faecal collection, a second brilliant blue capsule (Warner Jenkinson Europe) was administered on day 7 to mark the endpoint of the faecal collection period. All stool samples were collected separately, starting immediately after test meal administration. Faeces were collected until the second brilliant blue marker appeared. Urine was collected in parallel in $24 \mathrm{~h}$ pools until the end of day 6 . On day 14 , a venous blood sample $(10 \mathrm{ml})$ was drawn into a heparinised glass tube for $\mathrm{Mg}$ isotopic analysis of erythrocytes. Plasma was not analysed for its isotopic composition, as kinetic studies suggested a relatively low half-life of $\mathrm{Mg}$ in plasma, and therefore an isotopic enrichment too low for isotopic analysis at day 14 (Avioli \& Berman, 1966; Feillet-Coudray et al. 2002).

\section{Urine, stool and blood sampling}

Urine samples were collected in pre-weighed polyethylene containers (Semadeni, Ostermundingen, Switzerland). Each $24 \mathrm{~h}$ pool was weighed, a $50 \mathrm{~g}$ portion was removed and acidified with $0.5 \mathrm{~g} \quad 10 \mathrm{M}-\mathrm{HCl}$ before storage $\left(-25^{\circ} \mathrm{C}\right)$. Urine pools $(6 \mathrm{~d})$ were prepared by combining $1 \%$ of each $24 \mathrm{~h}$ pool by weight.

Stools were collected in pre-weighed polypropylene containers (Semadeni), freeze-dried (Modulyo, Edwards, North Bergen, NJ, USA), weighed and ground in a mortar. Two stool pools were prepared:

(1) $6 \mathrm{~d}$ stool pools: all stools collected from the appearance of the first brilliant blue marker until, but not including the stool dyed by the second brilliant blue marker (given on day 7). For preparation of the pools, $5 \%$ of each stool were taken by weight, combined and thoroughly mixed.

(2) three-stool pools: the first three consecutive stools after the appearance of the first brilliant blue marker, including the first dyed stool, were pooled by combining $5 \%$ of each stool by weight.

Venous blood samples $(10 \mathrm{ml})$ were centrifuged at $20^{\circ} \mathrm{C}$ at $500 \mathrm{~g}$ (Omnifuge 2.0 RS; Heraeus, Zurich, Switzerland) to separate plasma from blood cells. Blood cell fractions were washed three times with small portions $(2-3 \mathrm{ml})$ of physiological saline $(9 \mathrm{~g} \mathrm{NaCl} / 1)$. Washed blood cell fractions, containing almost exclusively erythrocytes, were stored in acid-washed polyethylene vials $\left(-25^{\circ} \mathrm{C}\right)$ for later analysis.

\section{Sample digestion}

Freeze-dried bread $(1 \mathrm{~g})$, acidified urine $(3 \mathrm{ml})$, blood plasma $(1 \mathrm{ml})$ and erythrocytes $(1 \mathrm{ml})$ were digested with a mixture of $14 \mathrm{M}-\mathrm{HNO}_{3}$ and $8.8 \mathrm{M}-\mathrm{H}_{2} \mathrm{O}_{2}$ (Merck), using a microwave (MLS 1200; MLS GmbH, Leutkirch, Germany). Faecal samples were dry-ashed in covered Pyrex glass beakers in a muffle furnace (M 110; Heraeus) at $550^{\circ} \mathrm{C}$ for $12 \mathrm{~h}$ after addition of $5 \mathrm{ml} 14 \mathrm{M}-\mathrm{HNO}_{3}$. The ashes were dissolved in $10 \mathrm{ml} 5 \mathrm{M}-\mathrm{HCl}$. Beakers were discarded after use.

\section{Sample preparation for isotopic analysis}

All samples were analysed in duplicate. $\mathrm{Mg}$ was separated from the digested samples by cation-exchange chromatography using a strongly acidic ion-exchange resin (AG 50W X-8, 200-400 mesh; Bio-Rad, Hercules, CA, USA). Portions of the digested stool, urine and erythrocyte samples, containing approximately $8.2 \mu \mathrm{mol}$ (faecal samples) or $2.5 \mu \mathrm{mol}$ (urinary and erythrocyte samples) $\mathrm{Mg}$, were evaporated to dryness and redissolved in $1 \mathrm{ml} 0.7$ $\mathrm{M}-\mathrm{HCl}$ and transferred onto the top of a column (Bio-Rad, $10 \mathrm{~mm}$ inner diameter), filled with the ion-exchange resin to a height of $70 \mathrm{~mm}$. The column was rinsed with $56 \mathrm{ml}$ $0.7 \mathrm{M}-\mathrm{HCl}$, followed by $24 \mathrm{ml} 0.9 \mathrm{M}-\mathrm{HCl}$ to elute $\mathrm{Na}$ and $\mathrm{K}$. Mg was eluted with $12 \mathrm{ml} 1.4 \mathrm{M}-\mathrm{HCl}$. The solution was evaporated to dryness and redissolved in $50 \mu \mathrm{l}$ water. $\mathrm{Mg}$ recovery was evaluated with a diluted $\mathrm{Mg}$ standard solution (Titrisol; Merck). At a recovery of 94.8 (SD 1.8) \% ( $n$ 10), potential $\mathrm{Mg}$ isotopic fractionation on the column as a possible source of systematic bias is negligible. Resins were regenerated with $30 \mathrm{ml} 6 \mathrm{M}-\mathrm{HCl}$ and renewed after the fifth run. Isotopic and elemental analysis was performed under blank control. Only acid-washed Teflon and polyethylene laboratory ware was used for sample processing. Portions of the ${ }^{26} \mathrm{Mg}$ isotope label were processed in parallel with each batch for blank monitoring from ion-exchange chromatography onwards. Sample contamination due to natural $\mathrm{Mg}$ was found to be $10 \cdot 3$ (SD 4.1) nmol ( $n 6$ ) for combined sample preparation and filament loading, which was $<0.5 \%$ of the Mg separated.

\section{Isotopic analysis by thermal ionisation-MS}

Faecal and urine samples were analysed for isotopic composition by loading about $20 \mathrm{nmol}$ separated $\mathrm{Mg}$ onto the metal surface of the evaporation filament of a double-Re filament ion source. $\mathrm{Mg}$ was coated with $5-10 \mu \mathrm{g}$ silicagel $100,0.8 \mu \mathrm{mol}$ boric acid and $30 \mathrm{nmol} \mathrm{Al}$ as $\mathrm{AlCl}_{3}$ (all chemicals from Merck). Compounds were loaded in aqueous solution and dried at $0.8 \mathrm{~A}$ after each step. Finally, the evaporation filament was heated to dull red heat (1.6 A) for $30 \mathrm{~s}$. The ionisation filament remained unloaded. Isotopic ratios were determined with a single-focusing magnetic sector field instrument (MAT 262; Finnigan MAT, Bremen, Germany), equipped with a Faraday cup multicollector device for simultaneous ion-beam detection. The evaporation filament was heated to $1230^{\circ} \mathrm{C}$ using a standardised procedure. The ionisation filament was heated gradually to $1250-1350^{\circ} \mathrm{C}$ until a stable $\mathrm{Mg}^{+}$ion beam of $1-2 \times 10^{-11} \mathrm{~A}$ was obtained. Each measurement consisted of thirty consecutive isotopic ratio measurements.

Reproducibility (five independent runs) was $0.2 \%$ (relative SD) for the ${ }^{24} \mathrm{Mg}:{ }^{25} \mathrm{Mg}$ isotopic ratio and $0.4 \%$ (relative $\mathrm{SD})$ for the ${ }^{24} \mathrm{Mg}:{ }^{26} \mathrm{Mg}$ isotopic ratio.

\section{Isotopic analysis by inductively coupled plasma-MS}

Isotopic enrichment of erythrocytes was found to be too low for isotopic analysis by thermal ionisation-MS. Erythrocyte $\mathrm{Mg}$ was, therefore, analysed by multicollector ICP-MS at higher precision. All ICP-MS measurements 
were carried out using a magnetic sector ICP-MS (IsoProbe; Micromass, Manchester, UK) equipped with a multi-collector system of nine Faraday cups. The sample introduction system consisted of a Micromist nebuliser and a Cinnabar spray chamber (both Glass Expansion, Romainmotier, Switzerland). The instrument utilises a hexapole collision cell for collisional focusing and interference reduction. The collision gases were $\mathrm{H}(1.0 \mathrm{ml} / \mathrm{min})$ and $\mathrm{He}(7.5 \mathrm{ml} / \mathrm{min})$.

Further studies using the high-resolution mode of the instrument revealed a small interference at mass 26 due to the formation of atomic or molecular ions in the ion source. This interference remained stable even with $\mathrm{NaCl}$ $(100 \mu \mathrm{g} / \mathrm{g})$ added to the measurement solution. No matrix effects on the measured isotopic ratios were observed. The interference on mass 26 was therefore corrected by the external blank subtraction.

The measurement sequence for each enriched sample was: NBS980 (standard reference material 980; National Institute of Standards and Technology, Gaithersburg, MD, USA), baseline sample, enriched sample, baseline sample and finally again NBS980. Drifts in mass discrimination were corrected by assuming a linear drift between the two measurements of the isotope reference material. Reproducibility (six independent runs) was $0.01 \%$ (relative $\mathrm{SD}$ ) for the ${ }^{24} \mathrm{Mg}:{ }^{25} \mathrm{Mg}$ isotopic ratio and $0.02 \%$ (relative SD) for the ${ }^{24} \mathrm{Mg}:{ }^{26} \mathrm{Mg}$ isotopic ratio. More details about the ICP-MS procedure applied can be obtained from Klingbeil et al. (2001).

\section{Magnesium and ytterbium}

Total Mg content of stool pools, plasma and bread rolls was determined after dilution of the digested samples by flame atomic absorption spectroscopy (SpectrAA 400; Varian, Mulgrave, Victoria, Australia) using standard procedures. A commercial Mg standard (Titrisol; Merck) was used for internal calibration (standard addition technique) to minimise matrix effects. Certified reference materials (Wheat Flour 1567a, National Bureau of Standards, Gaithersburg, MD, USA; Seronorm Trace Elements Serum, Nycomed, Oslo, Norway) were analysed in parallel for quality control. Yb was measured in the digested and diluted faecal samples by electrothermal atomic absorption spectroscopy, using an external calibration technique against a Yb standard solution (Titrisol; Merck).

\section{Calculations}

$\mathrm{Mg}$ absorption was calculated by five different techniques based on the molar amounts of the ${ }^{25} \mathrm{Mg}$ and ${ }^{26} \mathrm{Mg}$ isotope label in the samples, which were calculated based on double-isotope dilution principles (Walczyk et al. 1997; Sabatier et al. 2002). Molar amounts of isotope labels were calculated from measured isotope ratios, as the stable isotope labels used were not mono-isotopic. The ratio of the molar amounts of both isotope labels in the sample is referred to as their molar amount ratio in the following. Techniques involving quantification of both isotope labels (urinary monitoring, erythrocyte analysis and faecal monitoring after correction for re-excreted isotopic label) give the $\mathrm{TA}$ of $\mathrm{Mg}$ as the amount of oral isotope label absorbed by the intestine. Faecal monitoring based solely on the recovery of the oral isotope label in faeces delivers the $\mathrm{AA}$ of $\mathrm{Mg}$. The $\mathrm{AA}$ of $\mathrm{Mg}$ is generally lower than the TA, as it does not take into account the fraction of oral isotope label that has been absorbed and re-excreted into faeces during the faecal collection time.

Technique 1: true absorption via urinary monitoring of both isotope labels. TA (\% oral isotope label) was calculated from the molar amount ratio of oral and intravenous isotope label $\mathrm{n}_{25}: \mathrm{n}_{26}$ in $6 \mathrm{~d}$ pools (technique 1a) and $24 \mathrm{~h}$ pools collected $22-46 \mathrm{~h}$ after test meal intake (technique $1 \mathrm{~b})$ respectively:

$$
\mathrm{TA}(\%)=\frac{\mathrm{n}_{25}}{\mathrm{n}_{26}} \times \frac{\mathrm{D}_{\mathrm{iv}}}{\mathrm{D}_{0}} \times 100,
$$

where $D_{i v}$ is the amount isotope label injected ( $\left.\mu \mathrm{mol}\right)$ and $\mathrm{D}_{0}$ the amount oral isotope label ingested ( $\left.\mu \mathrm{mol}\right)$.

Technique 2: true absorption measured via isotopic analysis of erythrocytes. TA of the oral isotope label (\%) was calculated from the molar amount oral:intravenous isotope label ratio in erythrocytes drawn $14 \mathrm{~d}$ after isotope label administration. Calculations followed equation 1 using the amount ratio of both isotope labels $\mathrm{n}_{25}: \mathrm{n}_{26}$ in erythrocytes instead of those in urine.

Technique 3: apparent absorption via recovery of oral isotope label. AA (\%) was calculated as the difference between the amount of oral isotope label given $\left(D_{0}\right)$ and the amount excreted in faeces $\left(\mathrm{F}_{0}\right)$ in $\mu \mathrm{mol}$ for the $6 \mathrm{~d}$ faecal pools assuming a complete recovery of nonabsorbed oral isotope label (technique $3 \mathrm{a}$ ).

$$
\text { AA }(\%)=100 \times \frac{\mathrm{D}_{0}-\mathrm{F}_{0}}{\mathrm{D}_{0}} .
$$

For a shortened faecal collection period (technique $3 b$ ), apparent $\mathrm{Mg}$ absorption was calculated using equation 3 . Calculations were based on the first three consecutive stools after appearance of the first brilliant blue marker, including the first dyed stool. Incomplete recovery of the oral isotope label was corrected for by using the fraction of rare earth element recovered in faeces (\% REE):

$$
\text { AA }(\%)=100 \times\left(1-\frac{\mathrm{D}_{0}-\mathrm{F}_{0}}{\mathrm{D}_{0}}\right) \times \frac{100}{\% \mathrm{REE}} .
$$

Technique 4: true absorption via faecal monitoring of oral and intravenous isotope label. TA (\%) was derived from AA by correction for the molar amount of oral isotope label that was absorbed and excreted within the faecal collection period. The molar amount of intravenous label $\left(\mathrm{F}_{\mathrm{iv}}\right)$ recovered in the $6 \mathrm{~d}$ pools was used for correction (technique 4a).

$$
\text { TA }(\%)=100 \times\left(\frac{\left(\mathrm{D}_{0}-\mathrm{F}_{0}\right) / \mathrm{D}_{0}}{1-\mathrm{F}_{\mathrm{iv}} / \mathrm{D}_{\mathrm{iv}}}\right) .
$$

For a shortened faecal collection period covering three consecutive stools including the first dyed stool (technique $4 b$ ), incomplete recovery of the oral label was corrected via the recovery of the administered rare earth element in the 
faecal pool as described for technique $3 b$.

$$
\mathrm{TA}(\%)=100 \times\left(\frac{\left(\mathrm{D}_{0}-\mathrm{F}_{0}\right) / \mathrm{D}_{0}}{1-\mathrm{F}_{\mathrm{iv}} / \mathrm{D}_{\mathrm{iv}}}\right) \times \frac{100}{\% \mathrm{REE}} .
$$

\section{Statistics}

Calculations were performed using commercial spreadsheet software (Excel 97, Microsoft and SPSS 10.0; SPSS Inc., Chicago, IL, USA). ANOVA was made using a general linear model, followed by either a Bonferroni test or Student's paired two-tailed $t$ test to determine differences between methods. Statistical significance was considered for $P<0 \cdot 05$. Correlation between methods was evaluated by Pearson correlation coefficients. Normal distribution of absorption values was verified by skewness and the Kolmogorov-Smirnoff test. Homogeneity of variance between the methods was verified with Levene's test. Absorption values are presented as arithmetic means and standard deviations.

\section{Results}

One subject was excluded from the three-stool pool evaluation due to gastrointestinal problems, and one subject was excluded from the double-isotope evaluations due to incomplete intravenous injection. Plasma concentrations of $\mathrm{Mg}$ were 1.02 (range 0.92-1.22) (SD 0.09) $\mathrm{mmol} / \mathrm{l}$ ( $n$ 10; reported normal range $0.75-0.96 \mathrm{mmol} / \mathrm{l}$; Lowenstein \& Stanton, 1986). The native Mg content of the wheat bread was $1.91 \mathrm{mmol}$ per serving.

Mean $\mathrm{Mg}$ absorption from the wheat bread consumed with water varied from 32.9 to $44.2 \%$ (Table 1) based on the different techniques. AA values differed significantly from TA values $(6 \mathrm{~d}$ stool pools $P=0.001$, three-stool pools $P=0 \cdot 01)$. TA based on the $6 \mathrm{~d}$ urine pools was significantly lower than TA calculated using the other techniques $(P=0 \cdot 0003$, ANOVA). There were no significant differences between TA values based on the $24 \mathrm{~h}$ urine pools $(22-46 \mathrm{~h})$, erythrocyte analysis and the $6 \mathrm{~d}$ faecal pools or three-stool pools.

Brilliant blue appeared in faeces on day 1 or 2 in all subjects. Completeness of faecal collection was evaluated by the recovery of $\mathrm{Yb} ; 98.7$ (range 91.3-107.9) (SD 5.6) \% ( $n$ 10) was recovered in the $6 \mathrm{~d}$ stool pools. Mean duration of faeces collection using brilliant blue for marking the beginning and end of faeces collection was 6.3 (range 5-7) (SD 0.7) $\mathrm{d}$ for the $6 \mathrm{~d}$ faecal pools. Excretion of the ${ }^{25} \mathrm{Mg}$ label and of $\mathrm{Yb}$ measured in the three-stool pools were significantly correlated (Fig. $1 ; P<0.01$ ). Yb recovery in the three-stool pools, excreted within 3.0 (SD 0.9) d after intake of the isotope labels, was 80.5 (range 55.2-101.0) (SD 18.5) \% ( $n$ 9). AA and TA determined by faecal monitoring based on the $6 \mathrm{~d}$ stool pools and the three-stool pools were significantly correlated (AA $r 0.76, P<0.05$; TA $r 0.83, P<0.05$ ) as was TA based on $6 \mathrm{~d}$ and $24 \mathrm{~h}$ urine pools $(r 0.73, P<0.05) . \mathrm{Mg}$ absorption based on erythrocyte analysis was significantly correlated only to absorption based on the $24 \mathrm{~h}$ urine pools $(r 0.78, P<0.05)$.

A difference in isotopic composition between erythrocytes and $\mathrm{Mg}$ of non-biological origin was observed. Baseline $\mathrm{Mg}$ isotopic ratios in erythrocytes of ten subjects were greater by 2.1 (SD 0.3) and 3.6 (SD 0.8) \%o $\left({ }^{25} \mathrm{Mg}:{ }^{24} \mathrm{Mg}\right.$ and ${ }^{26} \mathrm{Mg}:{ }^{24} \mathrm{Mg}$ respectively) than the certified isotope

Table 1. Fractional magnesium absorption (\%) based on different stable isotope techniques ${ }^{\star} \dagger$

\begin{tabular}{|c|c|c|c|c|c|c|c|}
\hline \multirow{3}{*}{$\begin{array}{l}\text { Method... } \\
\text { Information... } \\
\text { Sample... } \\
\text { Technique... }\end{array}$} & \multirow{2}{*}{\multicolumn{2}{|c|}{$\frac{\text { Urinary monitoring }}{\text { True absorption }}$}} & \multirow{3}{*}{ 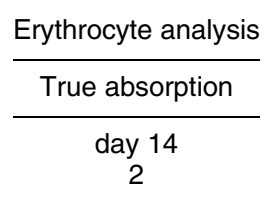 } & \multicolumn{4}{|c|}{ Faecal monitoring } \\
\hline & & & & \multicolumn{2}{|c|}{ Apparent absorption } & \multicolumn{2}{|c|}{ True absorption } \\
\hline & $\begin{array}{c}6 \mathrm{~d} \text { pool } \\
1 \mathrm{a}\end{array}$ & $\begin{array}{c}24 \mathrm{~h} \text { pool } \\
1 \mathrm{bf}\end{array}$ & & $\begin{array}{c}6 \mathrm{~d} \text { pool } \\
3 \mathrm{a}\end{array}$ & $\begin{array}{l}\text { three stool pool } \\
3 b\end{array}$ & $\begin{array}{c}6 \mathrm{~d} \text { pool } \\
4 \mathrm{a}\end{array}$ & $\begin{array}{l}\text { three stool pool } \\
4 \mathrm{~b}\end{array}$ \\
\hline Subject 1 & $26 \cdot 2$ & 37.9 & $34 \cdot 7$ & $39 \cdot 7$ & $34 \cdot 2$ & $51 \cdot 1$ & $42 \cdot 8$ \\
\hline Subject 2 & $43 \cdot 8$ & $50 \cdot 0$ & $51 \cdot 4$ & $52 \cdot 7$ & $47 \cdot 1$ & $63 \cdot 6$ & $52 \cdot 8$ \\
\hline Subject 3 & $43 \cdot 3$ & 55.5 & $49 \cdot 4$ & $44 \cdot 4$ & $43 \cdot 8$ & $47 \cdot 8$ & $50 \cdot 1$ \\
\hline Subject 4 & $28 \cdot 3$ & $34 \cdot 0$ & $38 \cdot 8$ & $36 \cdot 3$ & $36 \cdot 0$ & $40 \cdot 5$ & $37 \cdot 2$ \\
\hline Subject 5 & 24.5 & $45 \cdot 0$ & $45 \cdot 8$ & $29 \cdot 9$ & $36 \cdot 7$ & $32 \cdot 4$ & $39 \cdot 0$ \\
\hline Subject 6 & $35 \cdot 2$ & $51 \cdot 2$ & $48 \cdot 7$ & $36 \cdot 9$ & $41 \cdot 0$ & 48.5 & $41 \cdot 6$ \\
\hline Subject 7 & 29.9 & $39 \cdot 0$ & $30 \cdot 0$ & $32 \cdot 5$ & $39 \cdot 3$ & 38.9 & $40 \cdot 2$ \\
\hline Subject 8 & ND & ND & ND & $30 \cdot 1$ & $29 \cdot 2$ & ND & ND \\
\hline Subject 9 & 33.4 & $39 \cdot 1$ & 44.9 & $38 \cdot 1$ & ND & $48 \cdot 8$ & ND \\
\hline Subject 10 & 31.8 & $36 \cdot 9$ & 37.9 & $22 \cdot 8$ & 34.3 & $25 \cdot 7$ & $36 \cdot 7$ \\
\hline Mean & $32 \cdot 9^{a}$ & $43 \cdot 2^{b}$ & $42 \cdot 4^{\mathrm{b}}$ & $36 \cdot 3^{\mathrm{C}}$ & $38 \cdot 0^{C}$ & $44 \cdot 2^{b}$ & $42 \cdot 6^{b}$ \\
\hline SD of mean & 6.9 & $7 \cdot \overline{6}$ & 7.4 & $8 \cdot 4$ & 5.5 & $11 \cdot 2$ & 5.9 \\
\hline$\Delta\left({ }^{24} \mathrm{Mg}:{ }^{25} \mathrm{Mg}\right) \S$ & $5 \cdot 6$ & $6 \cdot 4$ & $1 \cdot 7$ & $15 \cdot 2$ & $28 \cdot 2$ & $15 \cdot 2$ & $28 \cdot 2$ \\
\hline SD of mean & 1.0 & $1 \cdot 1$ & 0.2 & $3 \cdot 1$ & $12 \cdot 4$ & $3 \cdot 1$ & $3 \cdot 1$ \\
\hline$\Delta\left({ }^{24} \mathrm{Mg}:{ }^{26} \mathrm{Mg}\right) \S$ & 4.4 & 3.9 & $1 \cdot 0$ & 0.8 & 0.9 & 0.8 & 0.9 \\
\hline SD of mean & 0.5 & 0.5 & 0.2 & 0.5 & 0.5 & 0.5 & 0.5 \\
\hline
\end{tabular}

ND, not determined.

a,b,c Mean absorption values within a row with unlike superscript letters were significantly different $(P<0.05)$

* For details of procedures, see p. 116.

†Isotope ratio measurements were determined by thermal ionisation-MS in urine and faeces and by inductively coupled plasma-MS in erythrocytes obtained $14 \mathrm{~d}$ after isotope administration.

$\ddagger$ Based on urine collected $22-46 \mathrm{~h}$ after test meal intake.

$\S$ Mean isotopic enrichments (\%) over baseline values in the sample material are given for the ${ }^{24} \mathrm{Mg}:{ }^{25} \mathrm{Mg}\left[\Delta\left({ }^{24} \mathrm{Mg}:{ }^{25} \mathrm{Mg}\right)\right]$ and the ${ }^{24} \mathrm{Mg}:{ }^{26} \mathrm{Mg}$ $\left[\Delta\left({ }^{24} \mathrm{Mg}:{ }^{26} \mathrm{Mg}\right)\right]$ isotope ratio, respectively. 


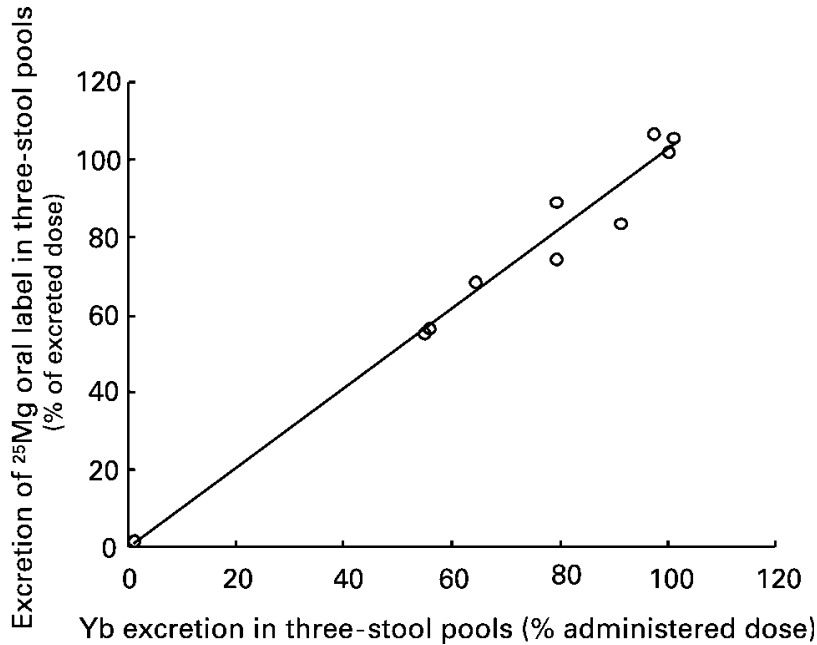

Fig. 1. Correlation between fractional excretion of the oral isotope label $\left({ }^{25} \mathrm{Mg}\right)$ and the quantitative faecal marker (ytterbium) in threestool pools $(y=1.024 x-0.241 ; R 0.99, P<0.01)$. Values are means for ten subjects.

reference material (NBS980; standard reference material 980; National Institute of Standards and Technology) $(P=0.00001, n 10)$.

\section{Discussion}

Our present results demonstrate for the first time that the molar amount ratio of orally ingested and intravenously administered $\mathrm{Mg}$ stable isotope labels in erythrocytes (technique 2) is a potentially useful technique to determine the TA of $\mathrm{Mg}$ in human subjects (see Table 1). The same is given for the urinary monitoring technique based on $24 \mathrm{~h}$ urine pools collected $22-46 \mathrm{~h}$ after test meal administration (technique 1b). For either technique, the TA of $\mathrm{Mg}$ from the test meal was not significantly different when compared with results obtained by the conventional double-isotope faecal-monitoring method (technique 4a). In addition, we have shown that the shorter three-stool pool method, corrected for incomplete faecal collections by excretion of $\mathrm{Yb}$ (techniques $3 \mathrm{~b}$ and $4 \mathrm{~b}$ ), resulted in similar $\mathrm{Mg}$ absorption results as the $6 \mathrm{~d}$ faecal-monitoring method (techniques $3 \mathrm{a}$ and $4 \mathrm{a}$ respectively). It appears, therefore, that any of the methods to determine the TA of $\mathrm{Mg}$ will give similar results when used to monitor dietary factors influencing $\mathrm{Mg}$ absorption, at least in a healthy young study population. The only method that resulted in a significantly lower TA relative to faecal monitoring was that based on the $6 \mathrm{~d}$ urine pools. As expected, TA (techniques $4 \mathrm{a}$ and $4 \mathrm{~b}$ respectively) was significantly higher than AA (technique $3 \mathrm{a}$ and $3 \mathrm{~b}$ respectively).

Erythrocytes are easily accessible and, without the need for complete faecal or urine collections, erythrocyte analysis of isotope labels would greatly reduce the time and labour needed to determine $\mathrm{Mg}$ absorption. The method assumes that, after absorption, the isotope label added as an extrinsic tag to a meal is metabolised in an identical way to an isotope label injected intravenously. Although injecting the isotope label intravenously as a bolus 15 min after consumption of a simple test meal appeared satisfactory in our present studies, the timing and duration of the infusion needs further evaluation with more complex meals. Fe absorption is routinely determined using erythrocyte incorporation of a single orally administered isotope label, assuming a mean erythrocyte incorporation of $80 \%$ after 14 d (Cook et al. 1972). In our present studies, about $1 \%$ of the absorbed oral dose was recovered in erythrocytes. Although further studies are needed to validate erythrocyte analysis as a method for determination of $\mathrm{Mg}$ absorption, this approach is supported by an earlier study in rats: there was no significant difference in absorption based on erythrocytes, plasma and urine samples collected $48 \mathrm{~h}$ (erythrocytes and plasma) or 36-48 h (urine) after oral and intravenous isotope label administration (Coudray et al. 1997). Isotopic analysis of erythrocytes, however, is more demanding. Isotopic enrichments in erythrocytes are significantly lower when compared with faecal pools and require more precise isotope ratio measurements to generate meaningful data.

Measurement of low isotopic enrichment in biological samples might be associated with an additional methodological problem. Natural isotopic abundances of an element can be altered, in principle, by physiological processes (Galimov, 1985). Using thermal ionisation-MS, no such effects were observed for $\mathrm{Mg}$ in faecal and urine baseline samples relative to a $\mathrm{Mg}$ standard of non-biological origin (Titrisol; Merck), but the more precise multicollector ICP-MS measurements revealed differences in $\mathrm{Mg}$ isotopic composition between erythrocytes and an isotope reference material of non-biological origin. This problem was overcome by measuring the enriched sample together with the baseline sample for each subject.

TA was also determined in the present study based on molar amounts of oral:intravenous isotope label ratio in urine. TA of $\mathrm{Mg}$ based on $6 \mathrm{~d}$ urine pools was, however, significantly lower $(P<0.05)$ compared with all other techniques of TA, including the $24 \mathrm{~h}$ urine pools (Table 1 ). Recently Sabatier et al. (2003) reported a significantly lower TA based on $3 \mathrm{~d}$ (days 1-3) urine pools compared with $12 \mathrm{~d}$ faecal pools. It has been suggested that absorption is underestimated when based on urine collected during the first hours after isotope label administration, because oral and intravenous labels are metabolised differently and absorption of the oral isotope label might not yet be complete (Abrams \& Wen, 1999; Sabatier et al. 2003). The inclusion of the first $24 \mathrm{~h}$ pools in our $6 \mathrm{~d}$ urine pools could thus explain the lower absorption value generated by the $6 \mathrm{~d}$ pools. In addition, a potential concern is the administration of the intravenous $\mathrm{Mg}$ label. Serum $\mathrm{Mg}$ levels are strictly regulated by the kidney (Elin, 1994). Thus, if the intravenous bolus results in a non-physiologically high level of free $\mathrm{Mg}$ in the blood, excess $\mathrm{Mg}$ may be rapidly excreted in urine, and the molar amounts of oral:injected isotope label ratio in urine will underestimate absorption in the first hours after isotope administration. To overcome this problem, Coudray et al. (1997) suggested that the intravenous dose should be infused over a long period of time or divided into several smaller doses. Our present findings indicate that a single intravenous bolus administered $15 \mathrm{~min}$ after the oral isotope label is suitable to determine $\mathrm{Mg}$ absorption, provided that urine collection is 
initiated later than about $22 \mathrm{~h}$ after isotope label administration; this is in agreement with the findings of Sabatier et al. (2003). It can be assumed that after about $22 \mathrm{~h}$, TA based on urinary monitoring of isotope labels corresponds to TA as determined by the conventional faecal-monitoring technique using an intravenous isotope label to correct for re-excreted oral isotope label.

The conventional method for measuring $\mathrm{Mg}$ absorption based on faecal monitoring of all non-absorbed isotope labels is time consuming and laborious. To determine TA by this technique, a second intravenous isotope label is necessary to estimate the amount of absorbed oral isotope label that is re-excreted during the faecal collection period. This makes the method as invasive and expensive as urinary monitoring or erythrocyte analysis of isotope labels. For paired comparisons, however, determination of $\mathrm{AA}$ of $\mathrm{Mg}$ by faecal monitoring remains the only option. Because both isotope labels are used for test meal labelling, no further isotope label is available for intravenous administration. TA of $\mathrm{Mg}$ is significantly underestimated by this method (Table 1), but it is less invasive and cheaper than other techniques as intravenous administration of a second isotope label is not required.

A major technical problem with faecal monitoring is the incomplete recovery of non-absorbed oral isotope label, either due to incomplete faecal collection by the subjects or due to prolonged gastrointestinal passage, resulting in an overestimate of absorption. This source of error was minimised in our present study by the use of brilliant blue to determine the starting point and the endpoint of the faecal collection period, and by using $\mathrm{Yb}$ as a nonabsorbable quantitative faecal marker for stool collection. Our present results indicate that faecal collections could be shortened from $6 \mathrm{~d}$ to three consecutive stools after excretion of the first dose of brilliant blue by correcting for incomplete recovery of isotope label using the rare earth element $\mathrm{Yb}$. In the three-stool pools, excretion of the oral $\mathrm{Mg}$ isotope label and $\mathrm{Yb}$ was significantly correlated (Fig. 1), and AA and TA determined by both techniques did not differ significantly (Table 1 , techniques $3 \mathrm{a}, 3 \mathrm{~b}$ and $4 \mathrm{a}, 4 \mathrm{~b}$ respectively). Gastrointestinal passage time of the oral $\mathrm{Mg}$ isotope label and $\mathrm{Yb}$ were relatively fast and the minimum recovery was $55 \%$ in the three-stool pools. Schuette et al. (1993) suggested that at least $40 \%$ of the rare earth element should be excreted in order to correct for incomplete collection, using Dy as a faecal marker to correct for $\mathrm{Mg}$ absorption. Although it can be assumed that many of the rare earth elements exhibit similar excretion patterns (Fairweather-Tait et al. 1997), we chose $\mathrm{Yb}$ rather than Dy or Sm because it could be detected with higher sensitivity by electrothermal-atomic absorption spectroscopy. In order to apply a correction by using a non-absorbable faecal marker, excretion patterns of $\mathrm{Mg}$ and the rare earth elements have to be similar. Based on the results from the present study, the shorter stool collection technique is well suited for studies in young healthy adults.

In conclusion, our present study showed that erythrocyte analysis of stable isotope labels $14 \mathrm{~d}$ after administration of an oral and an intravenous isotope label as well as monitoring of both labels in urine collected $22-46 \mathrm{~h}$ after isotope administration could be useful alternative methods to the faecal-monitoring technique to determine $\mathrm{Mg}$ absorption from food. If isotopic ratios can be measured at high precision, erythrocyte analysis offers a relatively simple technique avoiding faeces and urine collections. In addition, in a young healthy study population, $6 \mathrm{~d}$ faecal monitoring can be shortened to three consecutive stool pools by including $\mathrm{Yb}$ as a non-absorbable faecal marker.

\section{Acknowledgements}

We would like to thank Guido Fisher at the Cantonal Pharmacy Zurich, Switzerland, for preparing the intravenous doses, Michael Zimmermann for administration of the intravenous doses and Marlies Krähenbühl for drawing blood samples.

\section{References}

Abraham GE (1991) The importance of magnesium in the management of primary postmenopausal osteoporosis. J Nutr Med 2, 165-178.

Abrams SA \& Wen JP (1999) Methodologies for using stable isotopes to assess magnesium absorption and secretion in children. J Am Coll Nutr 18, 30-35.

Arvidsson B, Cederblad A, Bjorn-Rasmussen E \& Sandstrom B (1978) Radionuclide technique for studies of zinc-absorption in man. Int J Nucl Med Biol 5, 104-109.

Avioli LV \& Berman M (1966) Mg28 kinetics in man. J Appl Physiol 21, 1688-1694.

Catanzaro E (1966) Absolute isotopic abundance ratios and atomic weight of magnesium. J Res Natl Bur Std 70A, 453-458.

Cook JD, Finch CA, Walker R, Martinez C, Layrisse M \& Monsen E (1972) Food iron-absorption measured by an extrinsic tag. J Clin Invest 51, 805-815.

Coudray C, Pepin D, Tressol JC, Bellanger J \& Rayssiguier Y (1997) Study of magnesium bioavailability using stable isotopes and the inductively-coupled plasma mass spectrometry technique in the rat: single and double labelling approaches. $\mathrm{Br}$ J Nutr 77, 957-970.

DeGrazia JA, Ivanovic P, Fellows H \& Rich C (1965) A double isotope method for measurement of intestinal absorption of calcium in man. J Lab Clin Med 66, 822-829.

Durlach J (1988) Magnesium in Clinical Practice. London: John Libbey.

Elin RJ (1994) Magnesium: the fifth but forgotten electrolyte. Am $J$ Clin Pathol 102, 616-622.

Fairweather-Tait SJ, Minihane AM, Eagles J, Owen L \& Crews HM (1997) Rare earth elements as nonabsorbable faecal markers in studies of iron absorption. Am J Clin Nutr 65, 970-976.

Feillet-Coudray C, Coudray C, Tressol JC, Pepin D, Mazur A, Abrams SA \& Rayssiguier Y (2002) Exchangeable magnesium pool masses in healthy women: effects of magnesium supplementation. Am J Clin Nutr 75, 72-78.

Galimov EM (1985) The Biological Fractionation of Isotopes. Orlando, FL: Academic Press.

Kao WH, Folsom AR, Nieto FJ, Mo JP, Watson RL \& Brancati FL (1999) Serum and dietary magnesium and the risk for type 2 
diabetes mellitus: the atherosclerosis risk in communities study. Arch Intern Med 159, 2151-2159.

Karppanen H (1981) Epidemiological studies on the relationship between magnesium intake and cardiovascular diseases. Artery 9, 190-199.

Kastenmayer P, Davidsson L, Galan P, Cherouvrier F, Hercberg S \& Hurrell RF (1994) A double stable isotope technique for measuring iron absorption in infants. Br J Nutr 71, 411-424.

Klingbeil P, Vogl J, Pritzkow W, Riebe G \& Muller J (2001) Comparative studies on the certification of reference materials by ICP-MS and TIMS using isotope dilution procedures. Anal Chem 73, 1881-1888.

Lowenstein FW \& Stanton MF (1986) Serum magnesium levels in the United States, 1971-1974. J Am Coll Nutr 5, 399-414.

Sabatier M, Arnaud MJ, Kastenmayer P, Rytz A \& Barclay DV (2002) Meal effect on magnesium bioavailability from mineral water in healthy women. Am J Clin Nutr 75, 65-71.

Sabatier M, Keyes WR, Pont F, Arnaud MJ \& Turnlund JR (2003) Comparison of stable-isotope-tracer methods for the determination of magnesium absorption in humans. Am $J$ Clin Nutr 77, 1206-1212.

Schuette SA, Janghorbani M, Young VR \& Weaver CMJ (1993) Dysprosium as a nonabsorbable marker for studies of mineral absorption with stable isotope tracers in human subjects. $J$ Am Coll Nutr 12, 307-315.

Schwartz R, Spencer H \& Welsh JEJ (1984) Magnesium absorption in human subjects from leafy vegetables, intrinsically labeled with stable ${ }^{26} \mathrm{Mg}$. Am J Clin Nutr 39, 571-576.

Schwartz R, Spencer H \& Wentworth R-A (1978) Measurement of magnesium absorption in man using stable ${ }^{26} \mathrm{Mg}$ as a tracer. Clin Chim Acta 87, 265-273.

Tahiri M, Tressol JC, Arnaud J, et al. (2001) Five-week intake of short-chain fructo-oligosaccharides increases intestinal absorption and status of magnesium in postmenopausal women. $J$ Bone Miner Res 16, 2152-2160.

Walczyk T, Davidsson L, Zavaleta N \& Hurrell RF (1997) Stable isotope labels as a tool to determine the iron absorption by Peruvian school children from a breakfast meal. Fresenius $J$ Anal Chem 359, 445-449. 